\title{
ANÁLISE DAS ATIVIDADES DE GESTÃO DO CONHECIMENTO ENTRE EXTENSIONISTAS E EMPRESAS INCUBADAS: ESTUDO DE CASO DA INCUBADORA DA UNESC
}

\author{
KNOWLEDGE MANAGEMENT ACTIVITIES ANALYSIS BETWEEN \\ UNDERGRADUATE SCIENCE OUTREACH STUDENTS AND INCUBATED \\ ENTERPRISES: A CASE STUDY AT UNESC BUSINESS INCUBATOR
}

\author{
Guilherme Spiazzi dos Santos ${ }^{1}$ \\ Adriana Carvalho Pinto Vieira ${ }^{1}$ \\ Ricardo Pieri ${ }^{1}$ \\ Milla Lúcia Ferreira Guimarães ${ }^{1}$ \\ Thiago R. Fabris ${ }^{1}$ \\ Volmar Madeira $^{1}$
}

\begin{abstract}
RESUMO
O conhecimento apresenta grande relevância para a competitividade empresarial nos dias atuais e o seu gerenciamento propicia a fluidez de informação entre colaboradores e organização. Neste sentido, a manutenção do conhecimento se refere à identificação, classificação em categorias, armazenamento, beneficiamento, disseminação e uso. O presente estudo tem por objetivo analisar a influência da gestão do conhecimento nos trabalhos de três empresas de ramos distintos incubadas na Itec.in decorrente de um projeto de extensão na Universidade do Extremo Sul Catarinense. Por meio de reuniões foram transmitidos conhecimentos empíricos por parte dos incubados e formalizados através dos alunos, aplicando o Modelo Canvas para melhor visualizar o negócio de cada um e, posteriormente, foi realizada a construção individual do Plano de Negócios. Conclui-se que a influência na Gestão do Conhecimento para elaboração do Plano de Negócios proporciona a integração dos conhecimentos tácito e explícito dos empresários e extensionistas e desta forma a soma dos conhecimentos construídos complementam um ao outro.
\end{abstract}

Palavras-chave: Gestão do Conhecimento; Empresas Incubadas; Modelo Canvas; Plano de Negócios.

\footnotetext{
ABSTRACT

Knowledge is of direct relevance to business competitiveness in today and its management provides the flow of information between employees and organization. In this sense, the maintenance of knowledge concerns the identification, categorization, storage, processing, dissemination and use. This study aims to analyze the influence of knowledge management in three companies from different fields incubated at Itec.in and part of a science outreach program at University of Extremo Sul Catarinense. Through meetings the empirical

${ }^{1}$ Universidade do Extremo Sul Catarinense - UNESC.
} 
knowledge of these incubated enterprises was passed to the undergraduate science outreach students and formalized by them by applying the Business Model Canvas to better visualize each business. Subsequently the elaboration of a business plan for each company was carried out. This study concluded that the influence of the knowledge management at the elaboration of the business plan provides the integration of tacit and explicit knowledge of entrepreneurs and undergraduate science outreach students and thus the sum of the new formed knowledge complement each other.

Keywords: Knowledge Management; Incubated Enterprises; Business Model Canvas; Business Plan.

\section{INTRODUÇÃO}

A partir da globalização e a rápida mudança nos mercados houve quebra de paradigmas e as empresas passaram a utilizar o conhecimento como uma forma de ser mais competitivas. Precisaram realizar uma mudança estrutural no âmbito produtivo, focados principalmente no conhecimento, exigindo maior eficiência e eficácia das empresas. Conforme aponta North (2010, p. 2) "o desenvolvimento das tecnologias de informação nos últimos anos oferece a possibilidade de armazenar grandes quantidades de informação". A partir deste cenário, o processo de formação do conhecimento passa pela obtenção de informações pertinentes. E, da necessidade das organizações identificar, gerenciar e manter o conhecimento produzido dentro da mesma surgiu a Gestão do Conhecimento (GC). A teoria abre caminho para que a empresa mantenha sua competitividade no mercado por meio de converter os dois tipos de conhecimento que se formam por meio de dados que são convertidos em informação e transformados em conhecimento. Esta informação de posse da organização é constituída de dois saberes, o tácito e o explícito. O saber tácito pode ser compreendido como aquele empírico, resultado apenas da experiência em alguma atividade. Já o conhecimento explícito é entendido como a informação de interpretação e aquisição objetivas (NONAKA; TAKEUCHI, 1997; NORTH, 2010).

A valorização do capital intelectual nas organizações traz vantagens competitivas à organização quando esta identifica, codifica e compartilha conhecimentos de relevância estratégica. Portanto, pode se inferir que GC é uma impulsionadora da produtividade e inovação dos trabalhadores do conhecimento, tornando-a mais competitiva no mercado (TERRA, 2012).

Sales (2009) apresenta que nos países em desenvolvimento, como o Brasil, acompanham no decorrer das últimas décadas um significativo aumento de incubadoras de empresas. No entanto, segundo o SEBRAE (2012), as empresas não passam do seu terceiro ano de vida, relacionado a diversos fatores. E para minorar este dilema, um dos incentivos é a 
criação de um sistema favorável ao desenvolvimento e consciência da necessidade de alguns fatores, tais como: cultura empreendedora local, mecanismos adequados para que as atitudes empreendedoras sejam aprovadas e canalizadas com sucesso, infraestrutura, gestão da capacidade intelectual e do conhecimento (SALES, 2009, p. 323).

Deste modo, a universidade tem um papel fundamental, exigindo a expansão dos seus ativos físicos, organizacionais e educacionais de apoio à promoção da cultura empreendedora e tirar proveito das oportunidades geradas pelas atividades universitárias, propiciando a consolidação e desenvolvimento de novas empresas (SALES, 2009).

A partir desta contextualização, o presente estudo tem por objetivo analisar a influência da gestão do conhecimento na gestão empresarial das três empresas incubadas de ramos distintos através do projeto de extensão. O projeto será realizado na Incubadora Tecnológica de Ideias e Negócios (Itec.in) do Parque Científico e Tecnológico da Universidade do Extremo Sul Catarinense (UNESC) localizada na cidade de Criciúma no sul do Estado de Santa Catarina

A incubadora da Unesc - Itec.in - tem como objetivo estimular o surgimento de novos negócios de base tecnológica, fornecendo infraestrutura e apoio administrativo para a gestão efetiva do empreendimento (PIERI, 2012). Os serviços oferecidos pela Itec.in estão associados ao apoio necessário para o desenvolvimento das empresas incubadas e na capacitação dos seus respectivos proprietários para a autogestão de seus empreendimentos após o período de incubação (ITEC.IN, 2015).

Por meio da extensão universitária e decorrente da missão da Itec.in/Unesc o trabalho tem como ação promover assessoria na gestão, capacitação empresarial e de empreendedorismo para as empresas incubadas, contribuindo para a criação e desenvolvimento de empresas que ofereçam produtos ou serviços de base tecnológica. $\mathrm{O}$ projeto visa: a) Diagnosticar a situação atual dos empreendimentos incubados e criar uma rotina e cronograma de assessoria semanal para as empresa incubadas; b) Revisar o plano estratégico, operacional e de marketing do empreendimento, e seus respectivos planos de ação, adequando-os às condições do ambiente de negócio vivenciado pelo empreendedor e revisar as projeções econômico-financeiras do empreendimento, fazendo as adequações necessárias; c) Realizar levantamento das necessidades para criação de um programa de capacitação dos empreendedores; d) Estabelecer indicadores de controle do negócio e acompanhar o desenvolvimento das empresas incubadas.

Com relação à forma de trabalho da extensão universitária, a assessoria prestada às empresas incubadas é realizada por meio de ferramentas administrativas utilizadas por 
acadêmicos e professores. Dentre estas ferramentas encontra-se o Business Model Canvas (BMC), que segundo Clark et al. (2013) descreve de forma pontual e analisa o modelo de negócio organizacional ou uma lógica pela qual a empresa ganha seu sustento. Utilizar o BMC, para Werner (2013), é ter uma ferramenta que propicia à empresa uma melhor visibilidade do seu negócio, um olhar direto sobre a forma como ela cria, produz e canaliza soluções, valendo-se da criatividade e o conhecimento como recursos mais importantes. É uma aplicação lúdica, mas de impacto, de ideias a um negócio.

Posteriormente ao BMC é realizado o Plano de Negócios, pois este trabalha de forma criteriosa riscos, exigências, méritos e possíveis benefícios da organização e como ela faz uso deste conjunto de informações (DORNELAS et al., 2014).

A estrutura do trabalho se inicia com a contextualização da influência da gestão do conhecimento entre as empresas incubadas, acadêmicos e professores, apresentando ferramentas utilizadas no projeto de extensão para aplicação do conhecimento explícito. Em seguida são apresentados os procedimentos metodológicos aplicados para o desenvolvimento da pesquisa, a apresentação e discussão dos resultados, e por fim as considerações finais.

\section{GESTÃO DO CONHECIMENTO: TÁCITO E EXPLÍCITO}

A gestão do conhecimento pode ser encarada como uma abordagem holística da gerência da inovação. Além disso, Barroso e Gomes (1999) se referem de forma especial à capacidade de gerenciar, criar ou distribuir conhecimento de maneira eficaz e/ou eficiente como algo fundamental. Identificar e analisar os ativos intelectuais relacionados à empresa ou projeto e posteriormente a isso compartilhar as informações disponíveis e necessárias, além dos processos, gera novos conhecimentos e isto permite maior competitividade por promover um maior conhecimento a respeito do tema abordado.

Para Perilo (2009), a gestão do conhecimento também é a identificação, integração, recuperação, compartilhamento e utilização do conhecimento. Mas o que é o conhecimento senão uma bagagem de informações acumulada por meio do estudo técnico e também de experiências vividas na prática? É o saber acerca de um ou vários assuntos que forma o conhecimento.

No entendimento de Morin (2003), este conhecimento funciona a partir da seleção de dados significativos e o abandono de dados não significativos, de forma que estas informações podem ser separadas, associadas, categorizada e centralizada. Sob o ponto de vista de Japiassu (1998), o autor complementa dizendo que o conhecimento metodicamente 
obtido e de certa forma organizado tem a possibilidade de ser repassado de maneira pedagógica.

Há um paralelo entre o conhecimento técnico e o proveniente da prática, do qual, sob o ponto de vista de Sveiby (1998), o conhecimento será tácito quando for prático e pessoal, quando puder ser mudado, adaptado ou expandido de acordo com suas experiências. Este tipo de conhecimento é visto por Nonaka e Takeuchi (2008) como um conhecimento que não é facilmente visível, formalizado ou explicado, pois é de caráter individual e por isso a sua comunicação por vezes é complexa.

A transmissão do conhecimento tácito é visto por Lara (2004) como um processo dinâmico, uma vez que a única forma de acontecer é por meio do contato direto entre pessoas que possuem o conhecimento. O processo de inovação pode ser beneficiado pelo aspecto intrínseco do conhecimento tácito, pois este, de acordo com Terra (2001), é inconsciente e surge por meio de momentos de criatividade, predição de resultados ou tomadas de decisão apenas com base na intuição e sem explicação lógica.

A outra face do saber é chamada por Nonaka e Takeuchi (2008) de conhecimento explícito, aquele que pode ser facilmente visualizado na forma de palavras, sons e números. Desta forma ele pode ser facilmente agrupado e repassado de forma rápida entre indivíduos. Segundo Lara (2004) este tipo de conhecimento se constitui por meio da educação formal e também pela compreensão de fatos. Independente de características práticas ou teóricas, as informações trocadas entre indivíduos tende a expandir a visão e o conhecimento daquele que se submete ao aprendizado. Isto é reforçado por Sveiby (1998) quando afirma que a capacidade de fazer algo pode ser transferida de um indivíduo para outro por meio da informação ou pela prática.

No que tange a troca de conhecimento, Terra (2005) afirma que a transferência do conhecimento tácito acontece apenas por meio da ação individual, uma troca ocasionada pela convivência e intercâmbio de experiências. Esta troca é vista por Santos et al. (2001) como um processo intermediado pela prática ou reprodução. O Quadro 1 destaca os processos principais de combinação de conhecimento e sua transferência. 
Quadro 1. Principais processos de combinação de conhecimento e sua transferência.

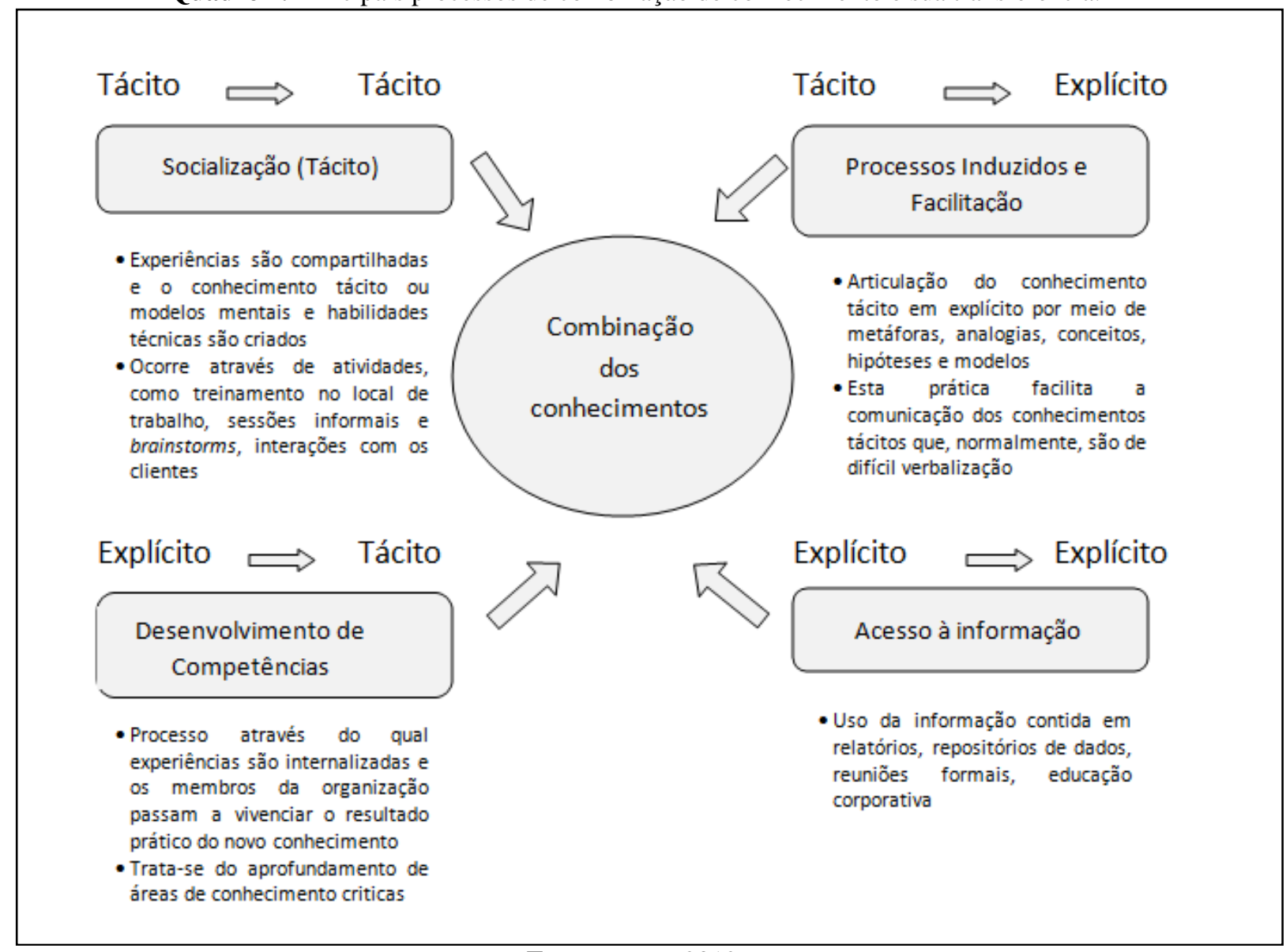

Fonte: Terra, 2012.

Para que o conhecimento seja extraído do indivíduo e então posto dentro de um contexto técnico, ou seja, para que o conhecimento tácito seja transformado em explícito, Lara (2004) diz que este 'saber' precisa ser externalizado, para então ser expresso de maneira lógica por meio de modelos, definições ou representações. Quando o conhecimento é formado por informações de diferentes fontes, este forma uma espécie de relatório, que por sua vez representa um novo conhecimento. Quando um indivíduo adquire o conhecimento por intermédio do estudo e o internaliza ele automaticamente começa a ampliar o próprio conhecimento tácito, no entendimento de Nonaka e Takeuchi (2008).

A passagem do conhecimento explícito para o tácito pode beneficiar a inovação e o contexto onde ele está inserido. Na visão de Lara (2004), o processo envolve a prática como forma de aprendizado. Dominar o conhecimento, saber aplicá-lo e conseguir transmiti-lo sempre foi importante e tem se tornado indispensável no mundo atual, onde cada vez mais governos, universidades e pessoas estão interligados, ora competindo entre si, ora unindo forças por um bem comum. 


\section{Instrumentos de análise: Business Model Canvas e Plano de Negócios}

O trabalho do projeto de extensão, juntamente com a Itec.in, faz uso de ferramentas administrativas para realizar a assessoria. Dentre elas está o Business Model Canvas (BMC), uma ferramenta que, no entendimento de Werner (2013), é capaz de proporcionar uma visualização prática da empresa, pois permite enxergar como a organização cria, produz e entrega soluções, usando o conhecimento e a criatividade como principais recursos. Este modelo de análise é visto por Clark et al. (2013) como uma forma de descrever e analisar o modelo de negócio organizacional ou uma lógica pela qual a empresa gera renda.

O BMC descreve como um modelo de negócios deve ser, demonstrado como um mapa visual. Cada um dos tópicos deste mapa ajuda a transformar o conhecimento tácito em informações explícitas e de fácil visualização para o empreendedor e seus colaboradores (CLARK et al., 2013).

Por permitir uma maior visibilidade e clareza com relação à empresa o BMC é considerado como uma ferramenta inicial de trabalho. Na sequência, a próxima ação dos extensionistas é a utilização do Plano de Negócios, tendo em vista que este trabalha de forma criteriosa as exigências, riscos, méritos e benefícios potenciais da empresa e como ela está sendo utilizada (DORNELAS et al., 2014).

O Quadro 2 demonstra as nove áreas que são trabalhadas no Business Model Canvas com as empresas, e em específico nas empresas incubadas para elaboração do presente estudo no projeto de extensão. 
Quadro 2. Demonstrativo das áreas trabalhadas Business Model Canvas.

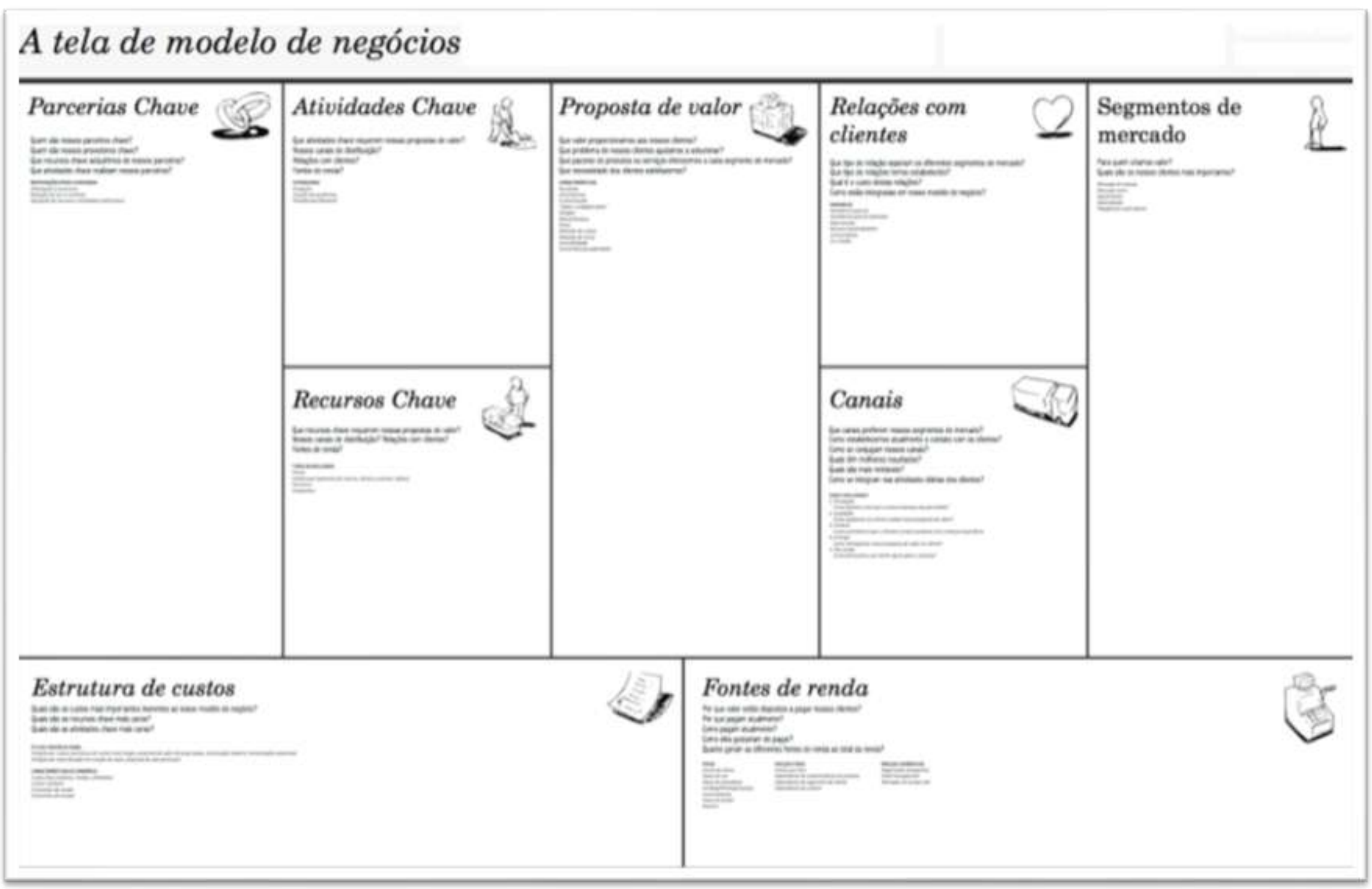

Fonte: Osterwalder, 2011. 
Já o Plano de Negócios (PN), segundo Oliveira (2014), se apresenta como um estudo estruturado do negócio pretendido pelo empreendimento, considerando todas as questões estratégicas, táticas e operacionais. A construção do PN deve ser entendida como o desenvolvimento estruturado e fundamentado do empreendimento para o empresário (CECCONELLO; AJZENTAL, 2008).

Este estudo pode ser visto como uma análise de viabilidade do empreendimento, pois, como afirma Oliveira (2014) auxilia na tomada de decisões uma vez que atua nas principais áreas de um empreendimento: estratégica, operacional, marketing e financeira.

\section{PROCEDIMENTOS METODOLÓGICOS}

O presente estudo se enquadra, quanto aos fins de investigação, como uma pesquisa descritiva, pelo fato do estudo pontuar e analisar o conhecimento tácito do incubado em relação às ferramentas utilizadas para a elaboração do projeto de assessoria, realizado por meio de um questionário e observação sistêmica (ANDRADE, 2007). É considerado como pesquisa aplicada devido ao estudo ser elaborado a campo com uma perspectiva operacional dos resultados coletados pelos extensionistas no Itec.in (FREIRE, 2013).

Quanto aos meios de investigação, a pesquisa classifica-se como estudo de campo e de caso. Um estudo de campo devido à observação sistêmica dos extensionistas e entrevistas realizadas periodicamente com os incubados (GIL, 2002). E estudo de caso, um método caracterizado como um estudo intensivo, em que todos os aspectos que envolvem o caso devem ser investigados. E, conforme o objetivo da investigação, a influência da gestão do conhecimento por meio do saber tácito e o saber explícito foram analisados dentro dos casos das empresas incubadas da Itec.in (FACHIN, 1993).

A abordagem da pesquisa descrita é qualitativa, o qual se busca interpretações profundas de três casos de empresas incubadas, que desenvolvem produtos e/ou serviços tecnologicamente inovadores (GIL, 2002). Assim o estudo almejou explanar o uso de teorias de Gestão do Conhecimento, bem como a análise dos instrumentos Business Model Canvas e Plano de Negócios.

O presente artigo está estruturado em forma de consultoria, onde os bolsistas, orientados pelos professores, revisarão e/ou desenvolverão semanalmente os planos empresarias junto aos empreendedores incubados. Nesta perspectiva, este trabalho não se limitará a um repasse de conceitos propriamente dito, tendo em vista que é realizado na forma de entrevista semi-estruturada em todas as visitas que são feitas nas empresas. Portanto, pode 
ser considerado que se trata de um processo de discussão, reflexão e orientação aos empresários para a gestão do empreendimento.

\section{APRESENTAÇÃO E DISCUSSÃO DOS RESULTADOS}

Destaca-se a seguir os dados coletados a partir da pesquisa, apresentando o contexto empresarial das três empresas incubadas analisadas, os pontos trabalhados com as ferramentas durante a análise e as percepções e expectativas em relação à transferência de conhecimento.

\section{Características Individuais das Empresas Incubadas}

As organizações em estudo serão caracterizadas como empresas A, B e C, e cada uma desenvolve produtos e/ou serviços tecnologicamente inovadores. A empresa 'A' tem como objetivo principal o ramo de biotecnologia voltada à agricultura. Porém, outros objetivos foram criados, fazendo com que a empresa ampliasse muito a sua área de atuação e, consequentemente, a partir deste fato, perdeu seu foco. Seu produto aplicado na agricultura é atualmente utilizado somente por uma empresa.

A empresa 'B' visa trabalhar na área de tecnologia da informação (TI) automatizando o fluxo de trabalho de agentes de trânsito, ao utilizar um coletor de dados dotado de comunicação por rádio frequência, que é parte de um sistema informatizado. O objetivo da empresa é otimizar o controle operacional de vagas de estacionamento, monitorar vagas livres e assegurar a rotatividade de veículos nas cidades.

A empresa 'C' atua na recuperação e preservação ambiental, presta serviços por meio da distribuição de um biorremediador. Os produtos comercializados são inovadores e de efeito imediato na redução dos impactos ambientais negativos.

\section{A INCUBADORA TÉCNOLÓGICA DE NEGÓCIO - Itec.in}

Segundo a Associação Nacional de Entidades Promotoras de Empreendimetnos Inovadores (ANPROTEC, 2014, p. 1), as incubadoras e seus parques tecnológicos são instituições que tem por objetivo realizar empreendimentos inovadores. E a incubadoras, por sua vez, tem por objetivo "oferecer suporte a empreendedores para que eles possam desenvolver ideias inovadoras e transformá-las em empreendimentos de sucesso".

Portanto, as incubadoras de empresas vinculadas a parques tecnológicos são instituições que auxiliam no desenvolvimento de micro e pequenas empresas nascentes e em operação. Elas oferecem suporte técnico, gerencial e formação complementar ao empreendedor. Segundo a Anprotec: 
De acordo com um estudo realizado em 2011 pela Anprotec, em parceria com o Ministério de Ciência, Tecnologia e Inovação (MCTI), o Brasil tem 384 incubadoras em operação, que abrigam 2.640 empresas, gerando 16.394 postos de trabalho. Essas incubadoras também já graduaram 2.509 empreendimentos, que hoje faturam $\mathrm{R} \$ 4,1$ bilhões e empregam 29.205 pessoas. O mesmo estudo revelou outro dado importante: $98 \%$ das empresas incubadas inovam, sendo que $28 \%$ com foco no âmbito local, $55 \%$ no nacional e $15 \%$ no mundial.

A partir deste cenário e acompanhando as mudanças que vem acontecendo nas últimas décadas como meio de promover o desenvolvimento socioeconômico equilibrado e sustentado, a Universidade do Extremo Sul Catarinense (UNESC) criou a Incubadora Tecnológica de Ideias e Negócios (Itec.in), que é uma unidade do Parque Científico e Tecnológico (Iparque), localizada na cidade de Criciúma no sul do Estado de Santa Catarina. A Itec.in tem como desafio e missão "Estimular a criação e o desenvolvimento de empresas que ofereçam produtos ou serviços tecnologicamente inovadores, disponibilizando o espaço apropriado e condições efetivas para abrigar ideias inovadoras e transformá-las em empreendimentos de sucesso" (UNESC, 2014).

A instalação da Itec.in dentro do Iparque traz às empresas incubadas a vantagem de, depois de graduadas, a possibilidade se instalar no próprio Parque Científico e Tecnológico, criando oportunidade para que as mesmas se desenvolvam num ambiente voltado à pesquisa e inovação (P\&D), além de contribuir para o desenvolvimento do corpo docente e discente da universidade e para a promoção do desenvolvimento socioeconômico regional equilibrado e sustentável (PIERI, 2012).

Atualmente, a Itec.in possui oito (8) empresas incubadas: três (3) empresas residentes, ou seja, estas empresas estão instaladas dentro do Iparque realizando a sua produção, e quatro (4) empresas não residentes, que não estão instaladas dentro do Iparque, realizando sua produção externamente, mas que por serem incubadas recebem toda assessoria da Itec.in.

Diante deste cenário, o projeto de extensão tem o intuito de promover ações de assessoria na gestão, capacitação empresarial e de empreendedorismo, por meio de professores e acadêmicos, para as empresas incubadas na Itec.in da UNESC, contribuindo para a criação, o desenvolvimento de empresas que ofereçam produtos ou serviços tecnologicamente inovadores. A pesquisa foi iniciada em 2014 e tem a participação de três (3) empresas incubadas que estão participando do projeto de extensão.

\section{0 intercâmbio de informação em prol dos objetivos do empreendimento}

Toda organização que deseja entrar ou se manter no mercado deve cuidar da saúde de sua estrutura, pois isto não acontece por acaso. Esta manutenção é feita por meio de uma série de análises e planejamentos a fim de gerar resultados positivos e outros fatores que 
impulsionem o negócio. Dentro deste contexto, as práticas e conceitos acerca da gestão do conhecimento podem aprimorar a visão das empresas incubadas. A informação proveniente do conhecimento explícito dos acadêmicos é apresentada para os gestores, para que assim possam entender os conceitos da academia e organizar suas ideias. Enquanto os empresários absorvem o conhecimento explícito, eles externalizam suas experiências, transmitindo o conhecimento tácito para a equipe de trabalho.

Mesmo tratando-se de três empresas de diferentes segmentos todas mostram necessidades muito semelhantes quanto à gestão dos negócios de maneira estratégica, técnica e objetiva. $\mathrm{O}$ trabalho realizado com as empresas incubadas tem como objetivo analisar a área financeira da organização, seu plano estratégico, o marketing e o seu plano operacional, por meio de encontros periódicos entre as equipes acadêmicas e cada um dos representantes das empresas envolvidas. O papel dos acadêmicos está na transferência do conhecimento explícito para os gestores, por meio de dados que são facilmente agregados e repassados de forma rápida (NONAKA; TAKEUCHI, 2008). E os empreendedores na transferência do conhecimento tácito, repassado de acordo com suas experiências (SVEIBY, 1998).

$\mathrm{O}$ início das atividades foi realizado com o BMC e posteriormente foi utilizado o instrumento do Plano de Negócios. Dentro do que aponta o BMC foi percebido que o aspecto visual em que foi realizado o trabalho auxiliou os gestores a entender como funciona o seu negócio. Inicialmente ficou evidente que ainda não era claro para os gestores das empresas A, B e C qual era o público-alvo. Apesar de todas conseguirem apresentar a sua proposta de valor, foi percebido que os canais de distribuição do seu produto e/ou serviço ainda não estavam definidos de forma efetiva. Conforme o grupo de extensionistas foi extraindo as informações dos gestores, diversas lacunas foram sendo preenchidas conforme prevê o roteiro do BMC. Em momentos de dúvida ou incerteza por parte dos gestores coube à equipe buscar as respostas através de perguntas-chave. Desta forma o BMC tomou sua forma completa e cada gestor pode enxergar o seu negócio de uma maneira holística, integrada e mais detalhada. Os gestores foram indagados pelos acadêmicos e professores de maneira objetiva, utilizando o conhecimento explícito desenvolvido com argumentos consistentes que fundamentem a elaboração e análises necessárias para o Plano de Negócio (CECCONELLO; AJZENTAL, 2008).

O diagnóstico envolvendo o BMC e o Plano de Negócios permitiu compreender de maneira lógica as ações que estão trazendo resultados positivos e negativos para o empreendimento. 
As informações passadas pelos gestores se resumiam nas suas experiências adquiridas com o negócio. A partir destas informações, coube aos alunos extensionistas transformar estes dados em informações para uma compreensão formal de todo o empreendimento. Corroborando com o pensamento de Santos et al. (2001), pode ser afirmado que a gestão do conhecimento leva as organizações à mensurar com mais segurança a sua eficiência, tomar decisões com mais certeza e segurança. Trata-se, portanto, da prática de agregar valor à informação, de distribuí-la e realizar o compartilhamento do conhecimento, conforme apontado pelos autores de GC (NONAKA; TAKEUCHI, 1997; NORTH, 2010).

Após a certeza da eficácia do método de trabalho pode-se continuar as análises seguindo o mesmo princípio. Questões de marketing, financeiro e operacional foram analisadas da mesma forma. No entanto, apesar da acessibilidade dos gestores das empresas incubadas, alguns obstáculos foram encontrados, pois houve relutância quanto a estudar o mercado de cada empreendimento, investigar a concorrência e até mesmo definir uma área principal de atuação da empresa. Como Nonaka e Takeuchi (2008) salientam em seus estudos, o conhecimento tácito não é facilmente visível, explicável ou formalizado. Ele é em essência algo altamente pessoal e por isso a sua comunicação é rebuscada e complexa.

A equipe de acadêmicos extensionistas teve como base o conhecimento explícito adquirido por meio do estudo nos cursos de graduação da UNESC e orientação dos professores do projeto de extensão. Além disso, o conhecimento tácito dos gestores foi agregado aos extensionistas, e da soma destes conhecimentos os acadêmicos expandiram sua visão e conhecimento tácito sobre a administração e a operação de cada organização trabalhada.

Com este saber compartilhado, os acadêmicos foram capazes de sintetizar o conhecimento e decodificá-lo na forma de palavras, que passaram a integrar os planejamentos e ações estratégicas das empresas envolvidas. Estes planejamentos e ações foram apresentados para os gestores para a sua indagação, interjeição, argumentação, aceite, negação e incorporação. A atividade realizada buscou unir a ciência da administração compartilhada pelos acadêmicos e professores com a experiência administrativa vivida pelos gestores com o objetivo de promover uma troca de informações e consequentemente a expansão do conhecimento.

\section{Transferência do conhecimento - percepção e expectativas}

O trabalho realizado pelos acadêmicos extensionistas e professores mostrou que os gestores tinham ciência da existência do Plano de Negócios e o BMC, mas não tinham noção 
da real importância destas duas ferramentas em prol do seu próprio empreendimento. Durante os encontros, os empresários mostraram serem detentores de conhecimento tácito em suas respectivas áreas, mas apresentaram certa defasagem no que se refere ao conhecimento explícito, que pode ser expresso por meio de palavras e números (NONAKA; TAKEUCHI, 2008).

A troca de conhecimento entre a equipe dos alunos extensionistas e as empresas incubadas provou beneficiar a gestão das organizações, pois o conhecimento aplicado passou a ser o conhecimento tácito dos gestores somado ao conhecimento explícito repassado pelos acadêmicos e professores. Esta soma de conhecimentos viabilizou a prática do Plano de Negócios desenvolvido e, assim, uma vez que um conhecimento complementa o outro, e uma vez que o conhecimento é formado por meio de dados que são convertidos em informação e transformados em conhecimento para todos os atores envolvidos, tanto das empresas incubadas, quanto aos alunos extensionistas e professores da universidade.

Durante os encontros, os gestores passaram o seu conhecimento e afirmaram ser fácil transmitir o seu conhecimento, identificado como tácito, sobre a empresa para a equipe. No entanto, este apontamento vai de encontro ao explicitado por Nonaka e Takeuchi (1997), pois os autores consideram que o conhecimento tácito é algo dificilmente visível e exprimível. É altamente pessoal e difícil de formalizar, o que dificulta sua transmissão e compartilhamento com outros. Porém, o que pode ser inferido que o receio das empresas está na publicação e na identificação da informação.

Ainda, foi percebido desde o inicio dos trabalhos dos alunos extensionistas com as empresas incubadas na Intec.in, que a visão dos gestores foi paulatinamente mudando conforme o BMC e o Plano de Negócios foram trabalhados. Isto somente foi possível por meio da transmissão do conhecimento explícito dos acadêmicos para os empresários. De posse de um novo conhecimento, os empresários puderam identificar e analisar o seu próprio empreendimento de forma mais precisa e com maior clareza, preparando-se para as oportunidades e dificuldades do mercado, bem como tornando evidente alguns pontos fracos que devem ser melhorados e os pontos fortes que devem ser valorizados.

Durante o trabalho realizado, o objetivo da equipe foi revisar o plano estratégico, operacional e de marketing do negócio, e seus respectivos planos de ação, adequando-os às condições do ambiente de negócio vivenciado pelo empreendedor; revisar as projeções econômico-financeiras do empreendimento, fazendo as adequações necessárias; realizar levantamento das necessidades para criação de um programa de capacitação dos empreendedores; estabelecer indicadores de controle do negócio e acompanhar o 
desenvolvimento das empresas incubadas. Diante disto, pode-se constatar que os gestores criaram expectativas com relação ao conhecimento explícito transmitido para eles, pois passaram a considerar melhorias e evolução na gestão de seus respectivos empreendimentos, maior foco nas principais atividades, maior efetividade, direção e objetividade no planejamento da organização, noção do mercado onde atua e visão estratégica mais apurada.

Assim, a equipe de alunos extensionistas tem expectativas de crescimento nos resultados das empresas incubadas da Itec.in. Além disso, espera-se que consigam administrar sozinhas os seus empreendimentos logo que se desligarem da incubadora, pois o que se espera a partir da análise da assessoria é que diminuam seus riscos no mercado. É importante destacar também que o conhecimento tácito transmitido pelos gestores foi de suma importância para os acadêmicos extensionistas, pois este contribui para a formação de cada um da equipe em seu respectivo curso de graduação.

\section{CONSIDERAÇÕES FINAIS}

O intercâmbio de informações entre os gestores assistidos e os acadêmicos e os acadêmicos extensionistas proporcionou respostas para várias questões relacionadas à maturação e manutenção de uma empresa no mercado. A constatação tornou evidente o fato de que o trabalho propiciou o desenvolvimento e aplicação de vários conceitos da administração e da gestão do conhecimento às empresas incubadas.

Mesmo considerando que os empresários envolvidos tinham conhecimento do BMC e o Plano de Negócios, ficou evidente que eles não haviam percebido o valor organizacional e estratégico destas ferramentas para os seus empreendimentos. A troca de conhecimento realizada enriqueceu a visão dos administradores e, além disto, foi percebido que a gestão do conhecimento proporciona uma troca infinita de informações entre as pessoas envolvidas e as empresas. Esta troca pode ser vista como uma vantagem competitiva num mercado que valoriza a inovação, sustentabilidade, qualidade e exige constante adaptação ao mundo globalizado.

Durante os encontros realizados pode-se perceber o ceticismo dando lugar à razão que o conhecimento proporcionou. Com a troca permanente de informações os acadêmicos puderam traçar um cenário individual de cada empresa e, juntamente com os gestores, trabalhar soluções para os problemas encontrados.

Apesar da disponibilidade dos gestores, o grupo de extensão encontrou algumas dificuldades no momento de obter determinadas informações. A falta de conhecimento quanto ao direcionamento do negócio, público-alvo, produção, atendimento, percepção da capacidade 
do próprio negócio e a realidade do mercado foram questões encontradas nas três empresas trabalhadas. Mesmo sendo questões básicas na gestão de qualquer negócio, todos mostraram defasagem de conhecimento nestas áreas. Este cenário talvez explique o porquê do insucesso de tantos empreendimentos nos dias atuais. Diante destes fatos, coube ao grupo de alunos extensionistas atuar nas questões mais pertinentes para que o empreendimento se mantenha sólido no mercado.

O escambo de informação e conhecimento trouxe resultados além do enriquecimento intelectual dos gestores, uma vez que o grupo acadêmico pôde expandir sua visão e experiência ao agregar todo o conhecimento tácito passado pelos empresários. Esta transmissão propiciou novas perspectivas com relação à realidade de muitas empresas. Este conhecimento adquirido certamente será levado e repassado adiante em futuros trabalhos com outros empreendedores.

Pode-se concluir que a vontade dos gestores de expandir o seu conhecimento vem ao encontro com a proposta da incubadora de negócios da Unesc, a Itec.in. A união de forças entre as partes pela busca do conhecimento enriquece o capital humano que está à frente de qualquer empreendimento.

\section{REFERÊNCIAS}

ANPROTEC - Associação Nacional de Entidades Promotoras de Empreendimentos Inovadores. Site da Anprotec. Disponível em: <http://anprotec.org.br/site/pt/incubadoras-e-parques/>. Acesso em: 20 ago. 2014.

ANPROTEC - Associação Nacional de Entidades Promotoras de Empreendimentos Inovadores. Estudo, Análise e Proposição sobre as Incubadoras de Empresas no Brasil - Relatório Técnico - Versão Resumida. Brasília: ANPROTEC, 2012. Disponível em: <http://www.anprotec.org.br/ArquivosDin/Estudo_de_Incubadoras_R esumo_web_22-06_FINAL_pdf_59.pdf>. Acesso em: 12 set. 2014.

BARROS, Antonio Carlos de Oliveira; GOMES, Elisabeth Braz Pereira. RAP, Rio de Janeiro, n. 2, p. 147-170, mar./abr.1999.

CECCONELLO, Antonio Renato; AJZENTAL, Alberto. A construção do plano de negócio: percurso metodológico para: caracterização da oportunidade, estruturação do projeto conceptual, compreensão do contexto, definição do negócio, desenvolvimento da estrategia, dimensionamento das operações, projeções de resultados, análise de viabilidade. São Paulo: Saraiva, 2008.

CLARK, Tim; OSTENWALDER, Alexander; PIGNEUR, Yves. Business model you: o modelo de negócios pessoal: o método de uma pagina para reinventar sua carreira. Rio de Janeiro: Alta Books, 2013.

DORNELAS, José; SPINELLI, Stephen; ADAMS, Robert. Criação de novos negócios: empreendedorismo para o século XXI. 2 ed. São Paulo: Elsevier, 2014. 
FACHIN, Odília. Fundamentos de metodologia. São Paulo: Atlas, 1993.

GIL, Antonio Carlos. Como elaborar projetos de pesquisa. 4 ed. São Paulo: Atlas, 2002.

JAPIASSU, Hilton. Introdução ao pensamento epistemológico. 5. ed. Rio de Janeiro: Francisco Alves. 1975.

LARA, Consuelo Rocha Dutra de. A atual gestão do conhecimento: A importância de avaliar e identificar o capital intelectual das organizações. São Paulo: Nobel, 2004.

MORIN, Edgar. Introdução ao pensamento complexo. 4. ed. Porto Alegre: Instituto Piaget, 2003.

NONAKA, Ikujiro; TAKEUCHI, Hirotaka. Criação de conhecimento na empresa: Como as empresas japonesas geram a dinâmica da inovação. 20 ed. Rio de Janeiro: Elsevier, 1997.

OLIVEIRA, Djalma de Pinho Rebouças de. Empreendedorismo: vocação, capacitação e atuação direcionadas para o plano de negócios. São Paulo: Atlas, 2014.

PERILLO, Mara. O conceito de gestão do conhceimento. Disponível em: $<$ http://www.administradores.com.br/artigos/negocios/o-conceito-de-gestao-doconhecimento/32153/>. Acesso em: 28 ago. 2014.

PIERI, Ricardo. Itec.in - Incubadora de Ideias e Negócios. Criciúma/SC: Unesc, 2012.

SALES, Davi I. Gestão de incubadora de empresas de base tecnológica: o caso Incamp. In: SANTOS, Marli Elizabeth Ritter; TOLEDO, Patrícia Tavares Magalhães; LOTUFO, Roberto de Alencar. Transferência de tecnologia: estratégias para a estruturação e gestão de núcleos de inovação tecnológica. Campinas: Komedi, 2009, p. 321-350.

SANTOS, Antônio Raimundo dos, PACHECO, Fernando Flávio; PEREIRA, Heitor; BASTOS JR, José Paulo Alberto. Gestão do conhecimento: Uma experiência para o sucesso empresarial. Curitiba: Champagnat, 2001.

SEBRAE - Serviço Brasileiro de Apoio às Micro e Pequenas Empresas. As incubadoras de empresas podem ajudar no seu negócio. Disponível em: $<$ http://www.sebraepr.com.br/PortalInternet/Noticia/ci.48\%25-das-empresas-

brasileiras-fecham-as-portas-depois-de-tr\%C3\%AAs-anos.print>. Acesso em: 22 ago. 2014.

SVEIBY, Karl Erik. A nova riqueza das organizações. 2. ed. Rio de Janeiro: Campus, 1998.

TAKEUCHI, Hirotaka; NONAKA Ikujiro. Gestão do conhecimento. Porto Alegre: Bookman, 2008.

TERRA, Jose Claudio Cyrineu. Gestão do conhecimento: O grande desafio empresarial. 2. ed. São Paulo: Negócio, 2001.

TERRA, Jose Claudio Cyrineu. Gestão do conhecimento: O grande desafio empresarial. Rio de Janeiro: Elsevier, 2005.

TERRA, Jose Claudio Cyrineu. 10 Dimensõe da gestão da inovação: uma abordagem para a transformação organizacional. Rio de Janeiro: Elsevier, 2012.

UNESC - Universidade do Extremo Sul Catarinense. Site da Itec.in. Disponível em: <http://www.unesc.net/portal/capa/index/357>. Acesso em: 20 ago. 2014.

UNESC - Universidade do Extremo Sul Catarinenses. Site da Itec.in. Disponível em: <http://www.unesc.net/portal/capa/index/357>. Acessado em: 13 set. 2014. 
ANÁLISE DAS ATIVIDADES DE GESTÃO DO CONHECIMENTO ENTRE EXTENSIONISTAS E EMPRESAS INCUBADAS: ESTUDO DE CASO DA INCUBADORA DA UNESC

WERNER, K. P. Como desenhar o seu jeito de fazer negócio (Canvas). Disponível em: <http://www.administradores.com.br/artigos/negocios/como-desenhar-o-seu-jeito-defazer-negocio-canvas/70326/>. Acesso em: 21 ago. 2014. 